\title{
Bioethical Problems of the Development of NBIC Technologies and Opportunities of Humanitarian Evaluation
}

\author{
Leonid Pisarchik $^{1, *}$ Galina Zavyalova ${ }^{1, \mathrm{a}}$ Vadim Nedorezov $^{1, \mathrm{~b}}$
}

\author{
${ }^{1}$ Orenburg State University, Orenburg, Russia \\ a'Email: lanser35@mail.ru \\ bEmail: nvad@yandex.ru \\ *Corresponding author. Email: leonidtp@yandex.ru
}

\begin{abstract}
Today the problems of social and humanitarian risks of the development of NBIC technologies (N nanotechnology, B - biotechnology, I - information technology, C - cognitive science) are widely discussed in the philosophical and scientific community. NBIC convergence is the supposed scientific basis of the VI technological structure, consisting in combining and mutually reinforcing the achievements of nano-, bio-, info- and cognitive technologies in order to solve the problems facing humanity. The article discusses the risks associated with these technologies. They are closely related to such problems as interdisciplinary examination and selection of optimal projects for the development of the techno-anthroposphere at the initial stage of the sixth technological structure, as well as the foresight methodology, the risks of making decisions in conditions of instability and working with BigData. In the context of bioethics, ethical evaluation of biomedicine is being studied. A broader sociotechnological examination and the development of ethical and value systems for forming the future are also needed. On this basis, global bioethics and humanitarian evaluation have been developed. The authors reveal the main aspects of humanitarian evaluation, its capabilities in determining risks and managing them.
\end{abstract}

Keywords: nanotechnology, convergent technologies, techno-anthroposphere, foresight, risks, BigData,

Internet of things, augmented reality, bioethics, global bioethics, humanitarian evaluation

\section{INTRODUCTION}

In the modern society, concerns about the risks associated with convergent technologies, which are increasingly used in science, economics, manufacturing and medicine, are growing. I.A. Aseeva writes:" ...G.G. Malinetskiy, coordinator of the project "System analysis and mathematical modeling of world dynamics", believes that the basis of the upcoming VI technological structure is formed by bio- and nanotechnologies, the construction of living things, the invasion into the human nature, new environmental management, smart medicine, robotics, high humanitarian technologies, designing and managing the future, technologies for the assembly and destruction of social subjects" [1]. In the previous five ways, mankind made the surrounding nature the subject of its activity and transformative activity, the 6th technological mode is not only associated with a change in nature, but is also aimed at changing ("improving") a person. It is planned to do this with the use of new convergent technologies, which gives rise to a social and humanitarian problem, that is, the problem of identifying and managing the risks associated with these technologies. Moreover, according to experts it is necessary to determine the risks and begin to eliminate them before the implementation of the projects themselves by predicting the social and humanitarian costs of new technologies in different phases of the VIth structure.

\section{MODERN TECHNOLOGY}

Modern technology science demonstrates the enormous potential of creating new equipment and new technologies. It creates unprecedented experimental conditions. To process huge volumes of information, physicists have created a global computer network GRID (GRID). This is a form of computing done by a supercomputer-like machine, which is a set of computers connected by a network. Such a grid system is used at CERN, the European Organization for 
Nuclear Research, where the World Wide Web was invented in the early 1990s, thereby providing a new significant increase in information exchange opportunities. Today, it has become possible to combine individual personal computers within a network into a single system, which makes the Internet itself similar to a supercomputer. G. Leonhard writes:" We are at the beginning of the global exponential development of the exponential curve in many areas of science and technology, that is, at a point where the growth of technological changes, calculated from each measured period to the next, is becoming more significant" [2]. Leonhard notes that the notion of exponential growth is based on G. Moore's law, according to which the performance of computing devices doubles every 18-24 months, at the same time they are getting smaller and cheaper.

During the first digital revolution, information technology became widespread. The basis of these processes was the expansion of personal computers, their application in all spheres of life and the growth of the Internet. Today is the second digital revolution. That is, if so far on the classical Internet exchanging messages by e-mail and other on-line channels was available only to people, now things are equipped with the appropriate hardware thanks to which they can also exchange messages. Thus, the Internet of Things (IoT) or the Internet of Everything has become a reality. In fact, this forms a huge array of information, called "Big Data" (BigData), which requires new technologies, special data banks and algorithms for processing. The technology of Big Data (BigData) is very important for the further development of scientific research. On this basis, the industrial Internet is now developing (Industry 4.0), which is the introduction of cyberphysical systems into production. "Industry 4.0 or the fourth industrial revolution is the era of innovation, which is characterized by the transition to fully automated digital production controlled by intelligent systems in real time. A new type of industrial production is based on technologies such as big data, automation, blockchain ${ }^{1}$, the Internet of things, artificial intelligence, smart networks" [3]. This industry is a strategic state-run program both abroad and in our country.

\section{NANOTECHNOLOGIES AND RISKS RELATED TO THEM}

The problem is that the NBIC convergent technologies, which are now being intensively developed, significantly complicate scientific research, industrial, market and communication processes, as

Blockchain is a distributed database containing information about all transactions. This information is stored and distributed among all participants in the system in the form of a chain of blocks containing information they are built on fast, efficient, self-adaptive algorithms. It leads to the fact that they are more difficult to administer. This system can turn into an uncontrolled superorganism. It is also significant that it is very difficult to predict the consequences of NBIC convergence, as well as the use of foresight technologies $^{2}$ in order to obtain scenarios for the development of the anthropotechnosphere.

The term "NBIC-technology convergence (N nanotechnology, B - biotechnology, I - information technology, C - cognitive science)" was introduced by the founders of this project $M$. Roko and W. Bainbridge. By this term they denote the processes in modern science. According to Roco and Bainbridge, NBIC technologies make it possible to solve many problems: to produce new materials, biological products and machines using nanotechnologies; "improve" a person; create communication interfaces of the brain and various electronic devices; create supercomputers; solve the problem of human aging using genetic engineering, etc. [4].

The term "nanotechnology" was first used in 1974 by the Japanese physicist Norio Taniguchi. Then E. Drexler proposed a model of a designer or universal assembler in "Machines of Creation: The Coming Era of Nanotechnology" in 1986, and then developed these ideas in the book "Nanosystems: Molecular Machines, Production and Computation" (1992). Drexler's nanoassembler can do almost anything with a high (atomic) degree of accuracy, including complex computers and elements for other assemblers. R. Kurzweil writes: "Although many configurations were proposed, a typical assembler was described as a desktop unit that can produce almost any physically possible product for which we have a description of the software, from computers, clothes and works of art to ready-made dishes" [5]. "The new technology, -Drexler writes, - will manipulate individual atoms and molecules under control and precision; let's call it molecular technology. It will change our world in more areas than we can imagine. Microcircuits have parts measured in micrometers - that is, in millionths of a meter, but molecules are measured in nanometers (thousand times smaller). We can use the terms "nanotechnology" and "molecular technology" interchangeably to describe a new type of technology. The developers of the new technology will build both nanocircuits and nanomachines" [6]. He calls these new nanomachines universal assemblers.

E. Drexler's speculative reasoning did not arouse support at that time. Many scientists doubted the

Foresight is a system of expert assessment methods for the most important strategic areas of socio-economic and technical innovative development, which allow determining the directions of accelerated development of the economy and society as a whole in the medium and long term. 
possibility of creating such assemblers, for example, the American physicist, Nobel laureate Richard Small [7]. But at the same time, they played a role in disseminating the ideas of nanotechnology and contributed to creation of administrative structures that guide the development of nanotechnology, and to receiving funding. This was especially obvious in the USA. Homo faber began to be regarded as the second God, and the idea of constructing the world atom by atom became the leading idea of nanotechnology. That is, nanotechnology is considered as a highly efficient technology and it has a wide range of capabilities. It functions as the basis for the development of NBIC convergence, stimulates the development of information, communication, biotechnological developments, etc.

Along with supporting the ideas of nanotechnology, there immediately arose an opposite movement, associated with the understanding of its consequences. Nanotechnology increases risks due to the multiple increase in the unreliability of real results, technologies and its materials. The spread of nanoparticles presents a great potential hazard to the environment and public health. This was stated in the study "Nanoethics (the ethical and social implication of nanotechnology)" (2007). Major experts in the field of nanotechnology warned:" ... nanoparticles can penetrate and accumulate in human tissues, developed molecules can selfassemble into artificial tissues, active nanosystems can evolve over time, nanoconstruction systems can combine with biological ones, systematic DNA control with the help of nanotools can change genetics" [8].

Nanobiotechnologies are based on the fact that they are used to manipulate individual atoms and molecules using the technologies of genomics ${ }^{3}$, proteomics ${ }^{4}$ and system biology. This product is used to operate living matter at the molecular level for therapeutic purposes. One can't but notice the success of biological science. What is impressive is another significant step forward in biotechnology. Scientists were able to experimentally integrate two fundamental natural processes - reading genetic information and protein synthesis. This was done by the outstanding scientist of our time Craig Venter, one of the founders of genetic engineering, under whose leadership the human gene was deciphered [9]. This will have enormous consequences for all of the mankind in the development of new approaches to solving energy, food, environmental and other critical problems. It is important that there is no negative

Genomics, as a branch of molecular genetics, studies the genome and genes of living organisms.

4 Proteomics is a field of molecular biology aimed at the identification and quantification of proteins. Moreover, the totality of all the proteins of the cell is called a proteome. It is the proteome that is the object of study of proteomics. reaction of the church and the general public to this event, as is the case with the evaluation of cloning.

Awareness of the risks associated with the development of nanotechnology has led to the emergence of ethics of nanotechnology. A. Grunwald writes:" The impetus for addressing ethical issues was the concern that a huge and growing gap was formed between rapid nanotechnological progress and insufficient study of its ethical consequences, which could lead to the fact that this development would become uncontrollable to society" [7].

The development of NBIC convergent technologies in recent decades has led to the formation of seemingly different worlds that complement each other, but at the same time are significantly different from each other. And this also indicates the emergence of new risks arising in the socio-anthroposphere. Among the wide variety of digital trends, researchers distinguish blockchain, augmented reality $(\mathrm{AR})^{5}$, and the boom of cryptocurrencies. Augmented reality is a mixture of the virtual and real worlds, that is, the physical and digital, in the creation of cyberphysical reality. The development of blockchain and augmented reality is reinforced by the trend of weak artificial intelligence, for example, the development of self-learning neural networks [10]. V.G. Budanov notes that within the framework of technogenic civilization, a person is included in various umwelts (Germ. Umwelt environment, habitat), that is, nearby human habitats [10]. There are four such umwelts: the natural environment, the technological environment, the neuroworld (or virtual world) and the network umwelt. "Umwelt analysis allows us to identify the basic challenges and risks of the development of the technoanthroposphere, their genetics and the prospects for their manageability" [1], - Budanov writes. The idea of umwelt analysis seems to be very promising.

\section{HUMANITARIAN EXAMINATION AND ITS OPPORTUNITIES}

The role of socio-humanitarian knowledge in techno-scientific development has become a subject of study in modern science and philosophy. The President of the European Research Council H. Novotny pointed out the vulnerability of the social and humanitarian sciences in connection with the spread of a narrow utilitarian approach to science and the expectation of immediate economic benefits from it [11]. E.G. Grebenshchikova notes that the humanities do not provide technical solutions, but "... the potential of socio-humanitarian approaches is becoming demanded both as a means of strategic forecasting, taking into account possible risks and negative effects, and as a

Augmented reality (AR) - a system in which virtual and real is combined. 
way to answer those questions that are already relevant to innovative development" [1].

When determining global megatrends of scientific research, the potential long-term negative consequences of the technical solutions for people and society should be discussed with the participation of humanitarian experts. Moreover, taking into account their purely engineering, instrumental and applied aspects is not enough. For example, some scientists believe that representatives of the social sciences can help in research in the field of synthetic biology by studying and thus preventing dangerous scenarios of the development of new technologies, and actively participate in these studies to warn of possible negative consequences well in advance.

A scientific group at the Massachusetts Institute of Technology (USA) understands synthetic biology as "... designing and constructing new biological parts, devices and systems, and redesigning existing natural biological systems for useful purposes" [12]. "In the last decade, governments and supporting organizatins around the world have begun to call for the integration of social issues and the problems of scientific practice. One of the ways often proposed to achieve this goal is to expand interdisciplinarity to include social sciences in technological and scientific activities in order to contribute to the development of "socially sustainable" technologies" [13]. For the first time, social sciences were integrated into the UK nanotechnology laboratory in 2003 at the suggestion of Professor Welland, director of the Center for Nanoscience at Cambridge University. Great Britain did not have a national research program in the field of nanotechnology, and the inclusion of social sciences in interdisciplinary research was left to the researchers themselves. Despite this, the cooperation between social sciences and specialists in the field of nanoscience was realized even more than in the United States [13].

In the course of development of modern science, three aspects relating to the problem of risks have been discovered: 1) science is a source of risks, 2) the scientific community has expert authority and 3) science serves as a means of resolving risky situations. This manifested itself in the 60s when discussing the consequences of the use of atomic weapons and the development of nuclear energy. Obviously "... inclusion of social actors in the design processes of scientific research and an assessment of their possible consequences" was necessary [14]. In the 70s and 80s, H. Novotny studied the problem of technological risks and became one of the authors of the concept of "socially reliable knowledge", which involves the transgression of evaluation into the real life, and in this process the expert must leave the boundaries of pure science and take the interests of a wide audience into account [14].
It is particularly difficult to assess long-term risks. Such an area of technoscience is biomedical knowledge. B.G. Yudin notes that "... the elements of risk and danger to which a human is exposed will inevitably increase together with the power of scientific knowledge which focuses on a person alongside with development of newer, more subtle and effective means of influencing people. Consequently, the task of protecting the person, for the sake of whom the progress of science and technology is carried out, from the negative consequences of this progress, is being actualized. As a result, the need to identify such consequences and react to them is extremely aggravated" [15].

The real possibilities of ethical evaluation are associated with the following aspects: 1) development of the competence of clinical ethics specialists; 2) improvement of the perception of moral problems by non-specialists; 3) development of various styles of moral reasoning; 4) development of professional selfawareness of ethics specialists [16]. "Ethics experts are currently the experts in various fields of professional life. They serve as members of government commissions, experts on international business groups, and advisers on selected political issues. Ethics are chairmen and members of ethics committees" [16].

I.T. Frolov and B.G. Yudin developed the ethics of science back in the 70 s and 80 s of the last century and considered a number of effective requirements and principles that facilitate the control and examination in human research processes see: $[17 ; 18 ; 19]$. The progress of science and technology cannot be stopped, and it must be carried out in the interests of man, but the problem is that in the modern world there is an urgent need to protect man "... from the negative consequences of the same progress" [20], — notes B.G. Yudin. To solve this problem in many countries social institutes of ethical support for biomedical research have been formed. And today, the ethical control of all research of this kind is the norm. In modern science, there are specially developed mechanisms for the ethical control of research. According to B.G. Yudin, there are three mechanisms for such control: 1) the informed consent to which each subject is entitled; 2) publication of the results of studies; 3 ) approval of the application for scientific research by the ethics committee [20]. Technological science of the 21st century as applied to human research has given rise to a completely new attitude of scientists towards value problems, that is, the value component of science becomes its integral feature. The imperative of our era is the direct influence of ethical standards on the course of scientific knowledge, since "... the demands set by ethics are among the effective prerequisites for scientific knowledge ..., in other words, the connection between ethics and science is not only possible, but also quite real" [20], — notes B.G. Yudin. But time also 
dictates the need for new solutions and approaches, as the need for nanoethics arose.

The founder of bioethics V.R. Potter, who wrote the book Bioethics "A Bridge to the Future" (1971), also proposed the development of global bioethics. "In the late 80 s of the XX century V.R. Potter suggests turning "bioethics 180 degrees". He is developing the concept of global bioethics as an all-encompassing and comprehensive ethics, the purpose of which is the acceptable survival of mankind" [21]. In this endeavor Potter is trying to synthesize medical ethics and environmental ethics. However, global bioethics can be understood in a different way. Henk ten Have, director of the Center for Health Ethics at Duquesne University in Pittsburgh (USA) and founder of the International Association for Ethics Education writes:" The panorama of bioethical issues today is different <...> The traditional bioethics that has developed over the past 50 years in Western countries is turning into a wider approach that is relevant for people around the world and is focused on new global problems" [22]. Henk ten Have draws attention to the fact that "... global bioethics is a necessity, since the social, economic and environmental consequences of globalization require critical reactions" [22]. This is really an urgent requirement of the time and one can only agree with this authoritative scientist.

\section{CONCLUSION}

The problems considered indicate that the tension in connection with the development of nanotechnology, biotechnology, digital technology and NBICconvergent technologies is growing. In recent decades, these processes have become the subject of research not only by specialists in the indicated fields, but also representatives of social and humanitarian knowledge, since the dangers are very great. This indicates a certain positive turn in these issues. Many also have concerns about the euphoria that has arisen in the mainstream of transhumanism ${ }^{6}$ in connection with the development of new technologies. Indeed, people need treatment for dangerous diseases, including hereditary ones, organ transplantation, and improving memory and physical condition. This goes without saying. But why should the development of technology abolish man and turn him into a cyborg, into a posthuman? This is the logic of technological progress, representatives of transhumanism respond. Or maybe a person will control such logic and such a technique? It would be more

6 Transhumanism (Latin trans - through, through, behind and homo - man) is a direction that studies the achievements of science and technology that can be applied to improve the physical and mental abilities of a person. Transhumanism also addresses the possibility of eliminating suffering, disease, aging and death. As the basis of all this, here we consider the convergence of nano, bio, information and cognitive technologies. reliable and correct. Based on the above stated, bioethics, global bioethics, nanoethics and humanitarian evaluation are extremely necessary for this. Experts in these fields, as we have shown, are quite able to combine their efforts with representatives of natural sciences and specialists in digital technologies in identifying risks and to steer the research on the right and safe course. Such precedents, as we see, already exist.

\section{References}

[1] Socio-humanitarian risks of the development of NBICStechnologies ("round table"), Philosophical sciences, No. 10, pp. 148-149, 2016.

[2] G. Leonhard, Technology versus man. Moscow: Publishing house AST, p. 31, 2018.

[3] Experts: the fourth industrial revolution will require legal transformation [Electronic resource]. Available at: https://nauka.tass.ru/nauka/6354637 (Accessed: 19.03.2020)

[4] P.P. Martinkus, "Paradoxes of the scientific revolution and convergent technologies", in Global Future 2045: Anthropological crisis. Converged Technologies. Transhumanist projects: Materials of the First All-Russian Conference, Belgorod, April 11-12, 2013 / ed. D.I. Dubrovsky, S.M. Climova. Moscow: «Canon+» ROOI «Rehabilitation», pp 130-132, 2014

[5] R. Kurzweil, The Singularity is Near: when humans trascend biology [Electronic resource]. Available at: https://www.grtl.org/Singularity-Is-Near.pdf (Accessed 8.03.2020)

[6] E. Drexler, Creation Machines: The Coming Era of Nanotechnology [Electronic Resource]. Available at: https://royallib.com/read/dreksler_erik/mashini_sozdaniya.html \#0 (Accessed: 8.03.2020)

[7] A. Grunwald. "Ethics for Nanotechnology" [Electronic Resource], Philosophy of Science and Technology, vol. 20, No. 1, p. 130, 2015. Available at: https://iphras.ru/uplfile/root/biblio/ps/ps20_1/126-143.pdf (Accessed: 23.11.2019)

[8] V.V. Ilyin. "Civilization paths of Homo Technologicus: the delicacy of existential situations" [Electronic resource], Russian Humanitarian Journal, vol. 8, No. 3, p. 166, 2019. Available at: http://libartrus.com/arch/files/2019/3/01_190464_Ilin_v3_165183.pdf (Accessed: 15.02.2020)

[9] O.V. Rudensky, O.P. Fisherman, "The 21st Century Innovative Civilization: The Convergence and Synergy of NBIC Technologies. Trends and forecasts 2015-2030", in Information and analytical bulletin of the CRSS, No. 3, p. 4, 2010

[10] Ibid., p. 137

[11] V.G. Budanov, "Socio-anthropological foresight and convergent technologies", NBIKS: Science. Technology, vol. 2, No. 2, p $48,2017$.

[12] Ibid., pp. 50-51.

[13] Idid., p. 156

[14] H. Nowotny, Shifting horizons for Europe's social sciences and humanities [Electronic resource]. Available at: https://www.theguardian.com/science/politicalscience/2013/sep/23/europe-social-sciences-humanities (Accessed: 5.03.2020)

[15] Ibid., p. 154 
[16] J. Calvert, P. Martin, "The role of social scientists in synthetic biology" [Electronic resource], EMBO reports, vol. 10, No. 3, pp. 201-204, 2009. Available at: https://www.embopress.org/doi/full/10.1038/embor.2009.15 (Accessed: 5.03.2020)

[17] R. Doubleday, A. Viseu, "Questioning Interdisciplinarity: What roles for laboratory based social science?" [Electronic resource], in Nano meets macro: Social Perspectives on Nanoscale Sciences and Technologies. University of Bergen, Norwey. Available https://www.researchgate.net/profile/Ana_Viseu2/publication/2 90829349_Questioning_interdisciplinarity_What_roles_for_lab oratory_based_social_science/links/5b56e922a6fdcc8dae4002ac /Questioning-interdisciplinarity-What-roles-for-laboratorybased-social-science.pdf (Accessed: 5.03.2020)

[18] Ibid.

[19] E.G. Grebenshchikova, "Dilemmas of expertise", in Humanitarian landmarks of scientific knowledge: Sat. Art. On the 70th anniversary of Boris Yudin / ed. P.D. Tishchenko. Moscow: Publishing house «Navigator», p. 186, 2014.

[20] [14] Ibid., p. 187.

[21] B.G. Yudin, "Technoscience, man, society: relevance of humanitarian expertise" [Electronic resource], Century of globalization, No. 2, 2008. Available at: https://gtmarket.ru/laboratory/expertize/5936 (Accessed: 14.03.2020)

[22] N.L. Steinkamp, B. Gordijn, Henk A.M.J. ten Have, ”Debating Ethical Expertise" [Electronic resource], Kennedy Institute of Ethics Journal, vol. 18, No. 2, p. 173, 2008. Available at: https://repository.ubn.ru.nl/bitstream/handle/2066/69564/69564. pdf? sequence $=1$ (Accessed: 14.03.2020)

[23] Ibid

[24] I.T. Frolov, Perspectives of man: the experience of integrated formulation, discussion, generalization. Moscow: Politizdat, 1979.

[25] I.T. Frolov, Philosophy and History of Genetics: Searches and Discussions. Moscow: Nauka, 1988.

[26] I.T. Frolov, B.G. Yudin, Ethics of Science: Search and Discussion. Moscow: Politizdat, 1986.

[27] B.G. Yudin, "Science in the knowledge society", in Humanitarian landmarks of scientific knowledge: Sat. Art. On the 70th anniversary of Boris Yudin / ed. P.D. Tishchenko. Moscow: Publishing house «Navigator», p. 183, 2014.

[28] Ibid., p. 183-184.

[29] Ibid., p. 184.

[30] C.V. Pustovit, Global bioethics: the formation of theory and practice (philosophical analysis) [Electronic resource]. Kiev: Arktur-A, 2009. Available at: https://studopedia.ru/9_177400_globalnaya-bioetika-vrpottera.html (Accessed: 16.03.2020)

[31] Henk ten Have, Global Bioethics: An introduction [Electronic resource]. Available https://pdfs.semanticscholar.org/5390/cc6cbb33d8857866d3edb 8393 cadf34bf56d.pdf?_ga $=2.208372050 .114579814 .158420010$ 1-1736922553.1584200101 (Accessed: 14.03.2020) 